\title{
APPLICATIONS OF DAMPERS FOR VIBRATION CONTROL OF STRUCTURES: AN OVERVIEW
}

\author{
Vajreshwari Umachagi $^{1}$, Katta Venkataramana ${ }^{2}$, G. R. Reddy ${ }^{3}$, Rajeev Verma ${ }^{4}$ \\ ${ }^{1,2}$ Department of Civil Engineering, NITK, Surathkal 575025 \\ ${ }^{3,4}$ Structural \& Seismic Engg Section, Reaction Safety Division, BARC, Trombay, Mumbai-400085 \\ vmumachagi@gmail.com,ven.nitk@gmail.com, rssred@barc.gov.in, rajeev_ballia@yahoo.co.in
}

\begin{abstract}
Dampers have become more popular recently for vibration control of structures, because of their safe, effective and economical design. This paper presents an overview of literature related to the behavior of dampers on seismically affected structures. The review includes different types of dampers like metallic dampers, viscoelastic dampers, frictional dampers etc.
\end{abstract}

Keywords: Seismic response, dampers, structural control systems.

\section{INTRODUCTION}

Over the past few decades world has experienced numerous devastating earthquakes, resulting in increased loss of human life due to collapse of buildings and severe structural damages. Occurrence of such damages during earthquakes clearly demonstrates the high seismic hazards and the structures like residential buildings, lifeline structures, historical structures and industrial structures need to be designed very carefully to protect from earthquakes. Structural design approach using seismic response control is now widely accepted and frequently applied in Civil Engineering. In recent years, much attention has been paid to the research and development of structural control techniques such as passive control system, active control system, and semi active control system giving special importance on improvement of wind and seismic responses of buildings and bridges. Passive control systems do not require any power supply. Active control systems require external power supply and operate based on sensors which are attached within the structures. Semi active control systems are combination of both passive and active control systems which require external power supply and they operate based on sensors attached to within the structures. But when there is no power supply, passive control systems control the vibration of structures. Both control systems can be used for strong wind motion and earthquakes. Serious efforts have been undertaken to develop the structural control concept into a workable technology and such devices are installed in structures.

\section{LITERATURE REVIEW}

Structural control systems increase the energy dissipation capacity of structures during an earthquake by converting mechanical energy into heat energy. Different kinds of energy dissipation systems are given below:
Tuned Mass Dampers (TMDs): Tuned mass dampers (TMDs) are as shown in Fig.1 (Chakraborty and Roy, 2011 [1]) comprising a mass, spring attached to the structure and are used for vibration control of structures when subjected to earthquake excitations. It is a frequency dependent device. Recently, much research has been carried out such as analytical, numerical, experimental and optimum solutions of structures to study the effectiveness of TMDs in reduction of seismic response of structures. The passive tuned mass damper (PTMD) was developed and implemented by Lin et al., 1999 [2] for seismic reduction of irregular buildings. Here, five real earthquakes were considered for numerical and statistical analysis of five storeys torsionally coupled building. Results demonstrate that PTMD effectively reduces the response on building during earthquake. Zuo et al., 2004 [3] have developed multi degree of freedom tuned mass damper. To obtain the optimal solution experiments were conducted sequentially to optimize the two degrees of freedom system. TMD can be tuned to damp the first two flexural modes of a free-free beam. Pinkaew et al., 2003 [4] have reported that structure with tuned mass damper was less effective for seismic damage reduction. Peter, 2006 [5] has discussed the theoretical and experimental studies on tuned mass damper for the seismic retrofitting of existing structures. Almazan et al., 2007 [6] have observed that new bidirectional and homogenous tuned mass dampers are very effective in reducing the seismic response of structures. Marano et al., 2007 [7] have proposed a linear tuned mass damper for seismic control of structures by using constrained reliability based on optimization technique. Further, Marano et al., 2010 [8] have investigated the optimum parameter of tuned mass damper for minimization of displacement of the structure. From the results it was concluded that the design variable mass of the TMD considered was more capable compared to the solutions obtained without it. 
Tuned Liquid Mass Dampers (TLDs): Tuned liquid mass damper basically consists of liquid sloshing tanks and liquid mass depth. Due to liquid sloshing, the damper response of TLDs is highly nonlinear in nature and also frequency dependent device. The effectiveness of TLD is increased by using multiple tuned mass dampers (MTLDs) in which number of liquid sloshing tanks are increased to reduce the dynamic response of the structures. These MTLDs can be used for high rise buildings to reduce the wind and earthquake vibrations. Advantages of TLDs are low initial and maintenance cost, easy to install as compared to TMDs. Fujino et al., 1992 [9] have developed 2D rectangular model of the tuned liquid damper (TLD) to reduce the dynamic response of structures. Experiments were performed to make out the characteristics of TLD and the interaction between the TLD and structure using the shake table test with a harmonic external loading. Chakraborty and Debbarma, 2011 [10] have examined the uncertainty of the bounded system parameters to study the optimum design of liquid column vibration absorber (LCVA) for seismic vibration control of structures. The LCVA is modeled as a SDOF system as shown in Fig. 2 which consists of stiffness of $\mathrm{k}_{0}$, mass of $\mathrm{m}_{0}$, structural damping $\mathrm{c}_{0}$, length of horizontal portion $\mathrm{B}_{\mathrm{h}}$ and length of vertical portion $\mathrm{L}_{\mathrm{e}}, \mathrm{x}(\mathrm{t}) \& \mathrm{y}(\mathrm{t})$ are horizontal and vertical displacements and $\ddot{Z}_{\mathrm{b}}(\mathrm{t})$ base acceleration due to earthquake ground motion. Results show that LCVA tends to reduce the level of uncertainty. It was also observed that neglecting the effect of system parameter uncertainty may overestimate the damper performance.

Friction Dampers: Friction dampers are as shown in Fig. 4 (Pall et al., 1980 [11]) work based on the mechanism of solid friction for dissipation of vibration energy. Mualla and

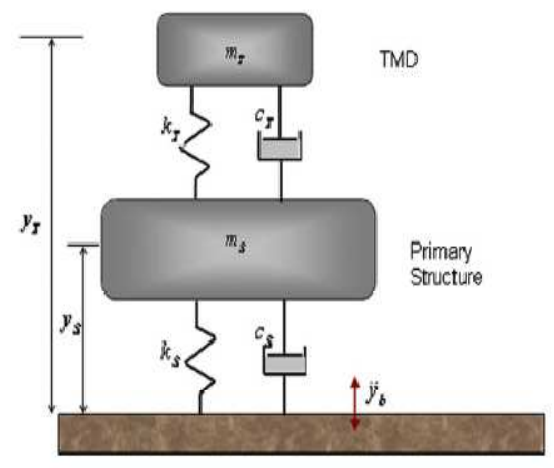

Fig.1 The primary structure with TMD system (Chakraborty and Roy, 2011[1])

Viscoelastic Dampers: Viscoelastic damper as shown in Fig. 7 (Soong and Spencer, 2002 [18]) consists of viscoelastic layers bonded with steel plates with viscous materials such as co-polymers or glassy substances. The energy is dissipated in
Borislav, 2002 [12] have investigated the performance of a friction damper installed in a single storey steel frame subjected to seismic loading. Experimental and numerical results show that the friction damper can improve the dynamic response of innovative structures as well as the existing building compared to the conventional design. The effectiveness of bidirectional frictional forces for the analysis of piping system when subjected to earthquake ground motion with friction supports was given by Jangid and Patil, 2009 [13]. The slotted bolt connection type friction damper was investigated on the seismic retrofitting of the structure by Robert Levy et al., 2001 [14]. The conceptual design of three storey steel frame building of seismic retrofitting of existing building using friction damper was investigated by Lee et al., 2008 [15] and Tabeshpour \& Ebrahimian, 2010 [16].

Metallic Dampers: First hysteretic dampers were implemented by Skinner et al., 1980 [17] for seismic protection of buildings. It was implemented to bridges and base isolated buildings. Metallic dampers were made up of mild steel plates as shown in Fig. 4 (Soong and Spencer, 2002 [18]). These devices dissipate energy through the inelastic deformation of metals. Thus, the purpose of metallic damper was increased in the dynamic response of structures and was implemented in full scale structures. Curadelli and Riera, 2004 [19] have proposed the metallic damper for seismic retrofitting of building frames based on reliability method. Vargas, 2007 [20] has investigated metallic damper with a viscous damper for reducing the dynamic response of single degree of freedom system (SDOF). Gang and Hongnan, 2008 [21] have presented new metallic damper with dual functions such as stiffness and seismic energy dissipation.

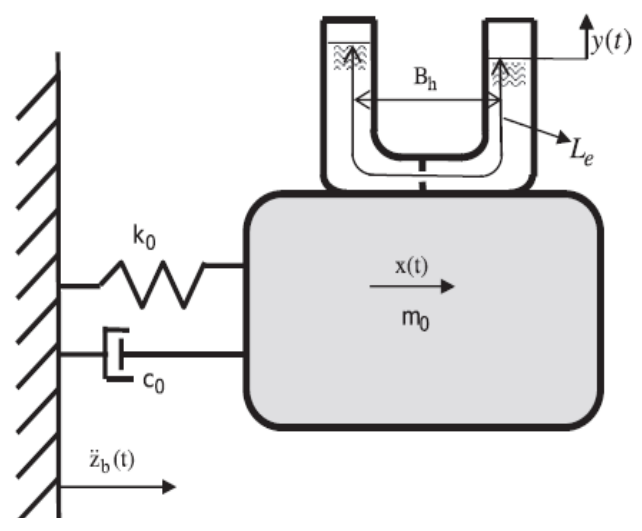

Fig. 2 The LCVA -SDOF system (Chakraborty and Debbarma, 2011 [10])

the form of shear deformation when mounted on a structure and they are highly dependent on ambient temperature and frequency excitation. Diclelia and Mehta, 2007 [22] have carried out parametric study of steel chevron braced frame 
system equipped with and without viscoelastic damper when subjected under seismic load. Choi and Kim, 2010 [23] have proposed new method of installing viscoelastic cables into building for seismic control of structures. Chen et al., 2010 [24] have analytically studied the seismic performance of wenchuan hospital structure using viscoelastic damper.

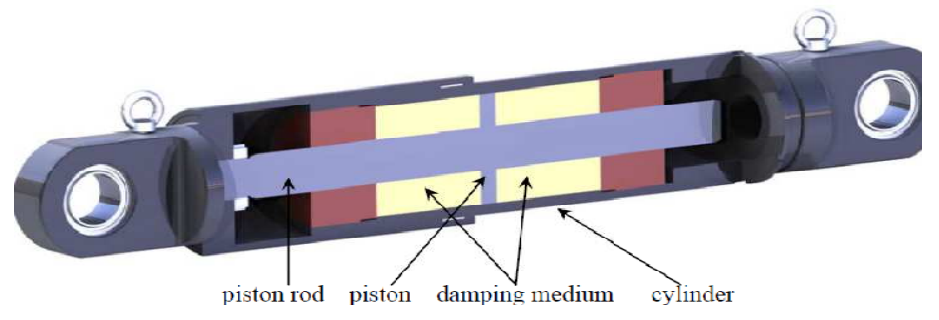

Fig. 3 A typical fluid viscous damper (Feng Qian et al., 2012 [25])

Viscous Dampers: Viscous dampers works based on fluid flow through orifices. Viscous damper is as shown in Fig.3 (Feng Qian et al., 2012 [25]) consisted viscous wall, piston with a number of small orifices, cover filled with a silicon or some liquid material like oil, through which the fluid pass from one side of the piston to the other. Stefano et al., 2010 [26] have manufactured the viscous damper and it was implemented in 3 storey building structure for seismic control

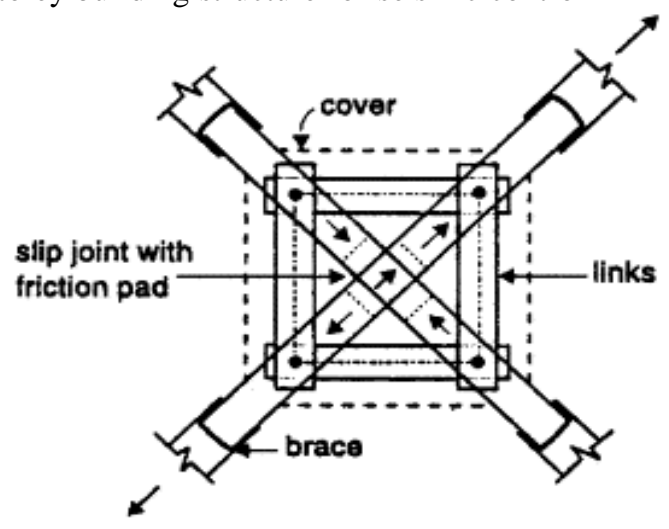

Fig. 4 Friction damper (Pall et al., 1980 [11])

Shape Memory Alloys (SMAs): Shape memory alloys are special kind of materials capable of retaining their original shape when heated at certain temperature. SMAs are as shown in Fig.5 (Sun et al., 2012 [31]) have great potential for use within the seismic resistant design and retrofit applications due to following properties i.e. energy dissipation capabilities, large elastic strain capacity, hysteretic damping, high and lowcycle fatigue resistance, re-centering capabilities and excellent corrosion resistance property. Applications of shape memory alloy in seismic control on structures like seismic rehabilitation of bridge, and in civil engineering structures. interstory displacement of steel building.

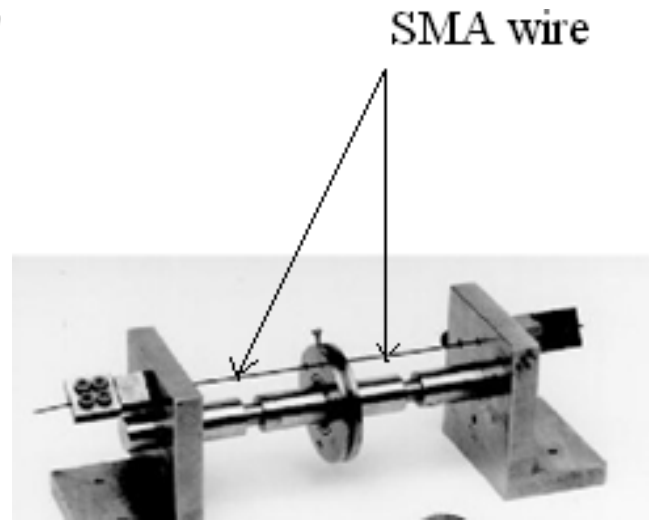

of structure with additional viscous damper. Attar et al., 2007 [27] have proposed optimal viscous damper to reduce the

Elasto Plastic Damper or X Plate Dampers: X plate dampers are thin metallic plates of $\mathrm{X}$ or $\mathrm{V}$ shape. They consist of single or group of plates and are made up of mild steel or copper material having different thicknesses. The mechanism of dissipating the energy of $\mathrm{X}$ plate damper is more effective during the earthquake by absorbing input energy of the structure. Satish Kumar et al., 2003 [28] have proposed an elastoplastic passive energy absorbing (PEA) devices as shown in Fig.8 and carried out the experimental and analytical studies to reduce large seismic deformation on pipelines when subjected to earthquake. Parulekar et al., 2009 [29] have discussed about retrofitting of reinforced concrete (RCC) structures by using elasto plastic damper (EPD) under seismic loads. Pujari and Bakre, 2011 [30] have studied the effect of $\mathrm{X}$ - plate damper (XPD) for seismic response control of structures. Dampers were located at 5 different places of square shaped multistoried building. One building frame considered was without XPD and one with XPDs in all bays and time history analysis was carried out using SAP2000. Numerical results show that the optimum location of XPDs was found to be most effective in reducing the seismic response of multistoried building.

Fig. 5 SMA wire based device (Sun et al., 2012 [31])

Baratta and Corbi, 2002 [32] have observed that SMA wires certainly improve the dynamic response capacity of structures. 

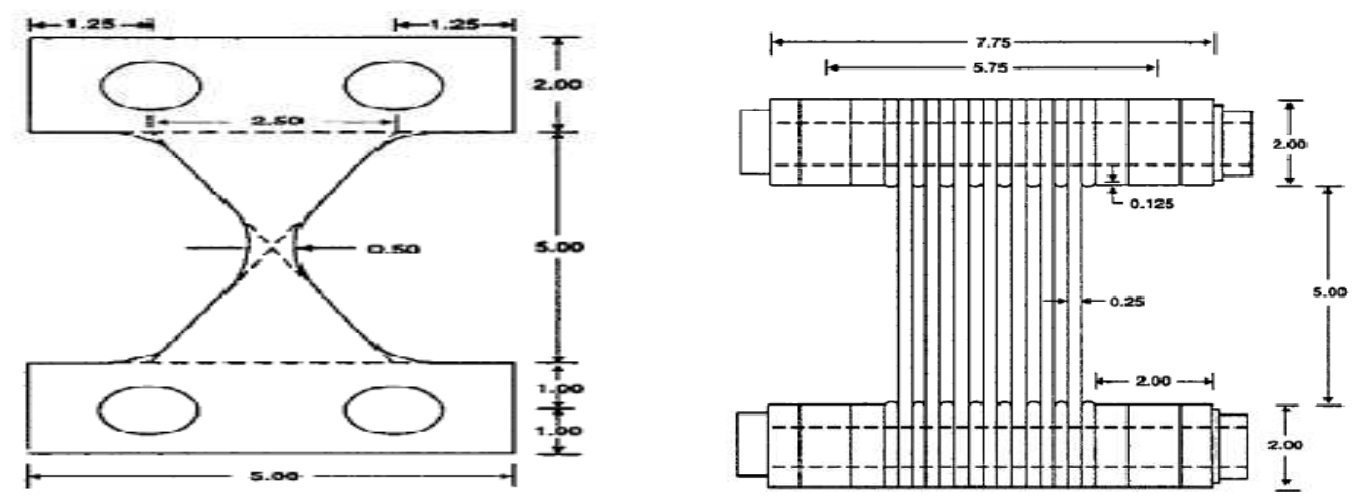

All dimensions are in inches

Fig. $6 \mathrm{X}$-shaped metallic damper or ADAS (added damping and stiffness) devices

(Soong and Spencer, 2002 [18])

Saadat et al., 2002 [33] have studied the unique thermo mechanical behavior of shape memory alloy and seismic applications of NiTi Shape memory alloys. Han, 2003 [34] has investigated a shape memory alloy wire based damper for seismic control of structures using finite element method. Justin et al., 2004 [35] have investigated the effectiveness of shape memory alloy connecting steel beam- column. Results show that energy dissipation from these connections is very high after being subjected to cycles up to $4 \%$ drift level. Ocel and Hurlebaus et al., 2010 [36] have given the overview of pseudoelasticity effect and characteristics of shape memory alloy and applications for passive, active and semi active seismic control of civil structures. Song et al., 2006 [37] have developed analytical models of concentrically braced frames with superelastic shape memory alloy (SMA) braces to

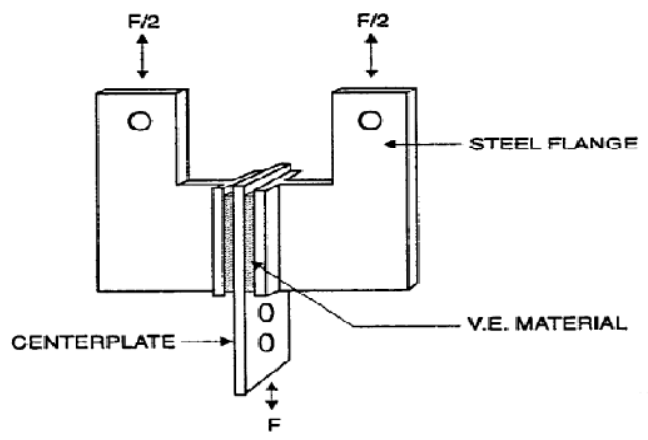

Fig. 7 Viscoelastic damper (Soong and Spencer, 2002 [18])

Later, Motaharia et al., 2007 [39] have discussed the passive energy dissipation systems and their modern applications for seismic protection of structures. Charney et al., 2008 [40] have developed the tension/compression device using NiTi shape evaluate the seismic performance of frames. The two chevrons (inverted V) braced of three and six story buildings were selected. The nonlinear dynamic time history analysis was carried out using the open system for Earthquake Engineering Simulation (OpenSEES) to determine the dynamic response of braced frames. The results demonstrate that the SMA braces are very effective compared to conventional methods. Jason et al., 2007 [38] have investigated four different types of shape memory alloy (SMA) dampers based on different crystallographic phases of SMA to reduce structural damage of the system during an earthquake. The different damper systems were implemented in a given structure and the behaviors of the systems were compared analytically with the buckling restrained steel bracing system.

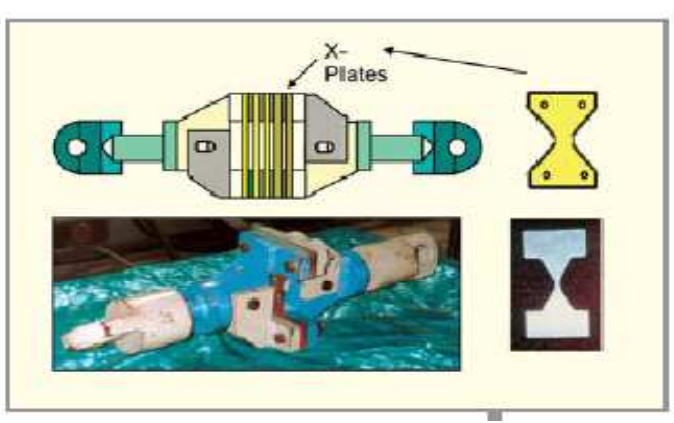

Fig. 8 Elasto plastic damper (Satish Kumar et al., 2003[28])

memory alloy. The designed elements were used as bracings in the building for seismic response control on structures. The proposed device showed good damping behavior to form the basis for a Nitinol damping devices. The seismic performance 
of a sliding-type base isolation system was studied by Matthew et al., 2009 [41] with the effect of temperature. A multi-span continuous bridge was modeled with a steel-Teflon sliding bearings and an SMA device. A multi-objective genetic algorithm optimization process was considered to obtain the design parameters of SMA device such as length and cross sectional of NiTi wires. Neuro-fuzzy model was used for simulating the superelastic behavior of NiTi shape memory alloys. A time domain method was used to generate the ground motion records for time history analysis of an isolated bridge, for a given design spectrum. Chuang et al., 2010 [42] and Mohamed Omar, 2011 [43] have investigated the design and analysis of steel braced frame structures with shape memory alloy braces for seismic control on structures. Sun et al., 2012 [31] did a review on three different stimuliresponsive SMMs, namely shape memory alloys (SMA), shape memory polymers (SMP) and newly emerged shape memory hybrids (SMHs) and also discussed their engineering applications and implementation in engineering design and practice.

\section{CONCLUSIONS}

Recently, use of seismic control systems has increased but choosing best damper and installing it into a building is very important for reducing vibration in structures when subjected to seismic loading. The controlling devices reduce damage significantly by increasing the structural safety, serviceability and prevent the building from collapse during the earthquake. Therefore many researches are being carried out to find the best solution. This paper attempts to provide an overview of different types of seismic response control devices, and highlights some of the recent developments. The experimental and analytical investigations carried out by various researchers clearly demonstrate that the seismic control method has the potential for improving the seismic performance of structures.

\section{ACKNOWLEDGEMENTS}

Authors gratefully acknowledge the financial support received from BARC, for carrying out this study.

\section{REFERENCES}

[1] S Chakraborty and B. K. Roy, "Reliability based optimum design of Tuned Mass Damper in seismic vibration control of structures with bounded uncertain parameters", Probabilistic Engineering Mechanics, Vol. 26, 2011, pp. 215-221.

[2] C. C. Lin et al., "Seismic response reduction of irregular buildings using passive tuned mass dampers", Engineering Structures, Vol.22, 1999, pp. 513-524.

[3] Zuo et al., "Optimization of multi-degree-of-freedom tuned-mass dampers", Journal of Sound and Vibration 272, 2004, pp. 893-908.
[4] Pinkaew et al., "Seismic effectiveness of tuned mass dampers for damage reduction of structures", Engineering Structures, Vol.25, 2003, pp. 39-46.

[5] N. Peter, "Tuned-Mass Systems for the Seismic Retrofit of Buildings", Seventh International Congress on Advances in Civil Engineering: 2006.

[6] J.L. Almazan et al., "A bidirectional and homogeneous tuned mass damper: A new device for passive control of vibrations", Engineering Structures, Vol.29, 2007, pp. $1548-1560$.

[7] G. C. Marano et al., "Constrained reliability-based optimization of linear tuned mass dampers for seismic control", International Journal of Solids and Structures, Vol.44, 2007, pp. 7370-7388.

[8] G. C. Marano et al, "A comparison between different optimization criteria for tuned mass dampers design", Journal of Sound and Vibration, Vol. 329, 2010, pp. 4880-4890.

[9] Fujino et al., "Tuned Liquid Damper for Suppressing Horizontal Motion of Structures", Journal of Engineering Mechanics (ASCE), Vol. 118, No. 10, 1992.

[10] Chakraborty and Debbarma, "Stochastic earthquake response control of structures by liquid column vibration absorber with uncertain bounded system parameters", Structural Safety, Vol. 33, 2011, pp. 136144.

[11] Pall. A. S et al., "Friction joints for seismic control of large panel structures", J. Prestressed Concrete Inst. Vol. 6, 1980, pp. 38-61.

[12] Mualla and B. Borislav, "Performance of Steel Frames with a new Friction Damper Device under Earthquake Excitation”, Engineering Structures, Vol. 24, 2002, pp. 365-371.

[13] R. S. Jangid and V. B. Patil, "Double Friction Dampers for Wind Excited Benchmark Building", International Journal of Applied Science and Engineering, Vol. 7, No. 2, 2009, pp. 95-114.

[14] Robert Levy et al., "A simple approach to the seismic design of friction damped braced medium-rise frames", Engineering Structures, Vol. 23, 2001, pp 250-259.

[15] Lee et al., "Design of a bracing-friction damper system for seismic retrofitting", Smart Structures and Systems, Vol. 4, No. 5, 2008, pp. 685-696.

[16] Tabeshpour and Ebrahimian, "Technical Note on Seismic Retrofit of Existing Structures Using Friction Dampers", Asian Journal of Civil Engineering (Building and housing) Vol. 11, No. 4, 2010, pp. 509520.

[17] R.J. Skinner et al., "Hysteresis dampers for earthquakeresistant structures", Earthquake Engineering and Structural Dynamics, Vol.3, 1980, pp. 287-96.

[18] T.T. Soong and B.F. Spencer, "Supplemental energy dissipation: state-of-the-art and state of-the practice", Engineering Structures, Vol.24, 2002, pp. 243-259. 
[19] R. O. Curadelli and J.D. Riera, "Reliability based assessment of the effectiveness of metallic dampers in buildings under seismic excitations", Engineering Structures, Vol. 26, 2004, pp. 1931-1938.

[20] Vargas, "Seismic Response of Hybrid Systems with Metallic and Viscous Dampers", Journal of Structural Engineering, Vol. 133, No.10, 2007.

[21] L. Gang and L. Hongnan, "Earthquake Resistant Design Of RC Frame with Dual Functions Metallic Dampers", The $14^{\text {th }}$ World Conference on Earthquake Engineering: 2008.

[22] Diclelia and Mehta, "Seismic performance of chevron braced steel frames with and without viscous fluid dampers as a function of ground motion and damper characteristics", Journal of Constructional Steel Research, Vol.63, 2007, pp.1102-1115.

[23] H Choi and J Kim, "New installation scheme for viscoelastic damper using cables", Can. J. Civ. Eng, Vol. 37, 2010, pp.1201-1211.

[24] X W Chen et al. "Seismic performance of Wenchuan Hospital Structure with Viscous Damper', Struct. Design Tall Spec. Build. Vol.19, 2010, pp. 397-419.

[25] Feng Qian et al., "Testing of Fluid Viscous Damper", 15th conference on World Conference on Earthquake Engineering: 2012.

[26] S. Stefano et al., "A Five-Step Procedure for the Dimensioning of Viscous Dampers to Be Inserted in Building Structures", Journal of Earthquake Engineering, Vol.14, 2010, pp. 417-447.

[27] T. L. Attar et al., "Controlling All Interstory Displacements in Highly Nonlinear Steel Buildings Using Optimal Viscous Damping”, Journal of Structural Engineering, Vol.133, 2007, pp. 0733-9445.

[28] K. Sathish Kumar et al., "Reduction of Large Seismic Deformations using Elasto-plastic Passive Energy Dissipaters ", Defence Science Journal, Vol. 53, No. 1, 2003, pp. 95-103.

[29] Y. M. Parulekar et al. "Seismic response analysis of RCC structure with yielding dampers using linearization techniques". Nuclear Engineering and Design, Vol.239, No.11, 2009, pp.3054-3061.

[30] N. N. Pujari and S. V. Bakre, "Optimum Placement of X-Plate Dampers for Seismic Response Control of Multistoried Buildings", International Journal of Earth Sciences and Engineering, Vol.4, No.6, 2011, pp. 481485 .

[31] L. Sun et al., "Review Stimulus-responsive shape memory materials: A review", Materials and Design, Vol.33, 2012, pp. 577-640.

[32] A. Baratta and O. Corbi, "On the dynamic behavior of elastic-plastic structures equipped with pseudoelastic SMA reinforcements", Computational Materials Science, Vol.25, 2002, pp.1-13.

[33] S. Saadat, et al., "An overview of vibration and seismic applications of NiTi shape memory alloy", Smart Mater. Struct. Vol.11, 2002, pp.218-229.
[34] Y.L. Han, "Structural vibration control by shape memory alloy damper", Earthquake Engng Struct Dyn, Vol.32, 2003, pp.483-494.

[35] O. Justin et al., "Steel Beam-Column Connections Using Shape Memory Alloys", Journal of Structural Engineering, Vol. 130, No.5, 2004, pp. 732-740.

[36] O. E. Ocel and S. Hurlebaus, "Evaluation of the performance of a sliding-type base isolation system with a NiTi shape memory alloy device considering temperature effects, Engineering Structures,Vol.32, 2010, pp. 238-249.

[37] G. Song et al., "Applications of shape memory alloys in civil structures”, Engineering Structures, Vol.28, 2006, pp. 1266-1274.

[38] M. Jason et al., "Seismic Assessment of Concentrically Braced Steel Frames with Shape Memory Alloy Braces", Journal of Structural Engineering, Vol. 133, No. 6, 2007, pp. 862-870.

[39] S.A. Motaharia et al., "Implementation of shape memory alloy dampers for passive control of structures subjected to seismic excitations", Journal of Constructional Steel Research, Vol.63, 2007, pp. 15701579 .

[40] Charney et al., "Energy Dissipation Systems for Seismic Applications: Current Practice and Recent Developments", Journal of Structural Engineering, Vol. 134, No. 1, 2008, pp. 3-21.

[41] Matthew et al., "Shape Memory Alloy Tension/Compression Device for Seismic Retrofit of Buildings”, JMEPEG, Vol. 18, 2009, pp.746- 753.

[42] Chuang et al., "Design and analysis of braced frames with shape memory alloy and energy-absorbing hybrid devices", Engineering Structures, Vol.32, 2010, pp. 498-507.

[43] Mohamed Omar, "Analytical Prediction of Seismic Response of Steel Frames with Superelastic Shape Memory Alloy World Academy of Science", Engineering and Technology, Vol. 59, 2011. 